\title{
MicroRNA-221 regulates cell activity and apoptosis in acute lymphoblastic leukemia via regulating PTEN
}

\author{
LINGYAN ZHANG, ZIBIN BU, JUAN SHEN, LIPING SHANG, \\ YUANYUAN CHEN, PING ZHANG and YAN WANG
}

\begin{abstract}
Department of Hematology and Oncology, The Children's Hospital, Zhejiang University School of Medicine, National Clinical Research Center For Child Health, Hangzhou, Zhejiang 310003, P.R. China
\end{abstract}

Received January 16, 2019; Accepted July 16, 2021

DOI: $10.3892 /$ etm.2021.10567

\begin{abstract}
T cell acute lymphoblastic leukemia (T-ALL), an aggressive and heterogeneous malignancy originating from $\mathrm{T}$ cell precursors (thymocytes), accounts for $\sim 15 \%$ of all ALL cases in children and for $\sim 25 \%$ in adults. The present study aimed to investigate the role of microRNA-221 (miR-221) in the regulation of cell viability and apoptosis of human T-ALL cells and its related regulatory mechanisms. To perform this investigation, miR-221 was upregulated or knocked down in human T-ALL cells (Jurkat cells) using miR-221 mimic or inhibitor, respectively. Then, cell viability was determined using a 3-(4,5-dimethylthiahiazol-2-y1)-2,5-diphenytetrazolium bromide assay, cell invasion and migration were analyzed via Transwell assays, and cell apoptosis was detected using flow cytometry. It was found that transfection with a miR-221 inhibitor significantly inhibited Jurkat cell viability, migration and invasion, and induced Jurkat cell apoptosis. Whereas, transfection with the miR-221 mimic resulted in the opposite effects. Besides, the results showed that phosphatase and tensin homologue deleted on chromosome 10 (PTEN) was a target of miR-221. Moreover, it was observed that the effects of the miR-221 inhibitor on Jurkat cell viability, migration and invasion, and cell apoptosis were significantly eliminated by PTEN-small interfering RNA. In addition, it was shown that the phosphatidylinositol 3-kinase/AKT pathway was involved in the effect of miR-221 on Jurkat cells. In conclusion, the data indicated that miR-221 existed as an oncogene in T-ALL, and its downregulation could inhibit the development of ALL by targeting PTEN. Therefore, miR-221 may be a novel potential therapeutic target for ALL.
\end{abstract}

Correspondence to: Dr Lingyan Zhang, Department of Hematology and Oncology, The Children's Hospital, Zhejiang University School of Medicine, National Clinical Research Center For Child Health, 57 Zhuganxiang Road, Hangzhou, Zhejiang 310003, P.R. China

E-mail: zhanglingyan77@zju.edu.cn

Key words: microRNA-221, phosphatase and tensin homologue deleted on chromosome 10, acute lymphoblastic leukemia, apoptosis

\section{Introduction}

Acute lymphoblastic leukemia (ALL) is a hematological malignant tumor characterized by a large number of immature leukocytes caused by abnormal lymphoblastic proliferation and abnormal differentiation, and it is a common type of childhood leukemia $(1,2)$. In recent years, despite clinical advances in the diagnosis and treatment of ALL, patients with ALL, especially those with refractory or relapsed ALL, still have a poor prognosis, serious adverse events and low survival rates (3-5). T cell ALL (T-ALL), an aggressive and heterogeneous malignancy originating from $\mathrm{T}$ cell precursors (thymocytes), accounts for $\sim 15 \%$ of all ALL cases in children and for $\sim 25 \%$ in adults $(6,7)$. Currently, the outcomes for T-ALL are still lagging behind by $5-10 \%$ compared with B cell ALL in most studies $(8,9)$. Therefore, it is of great significance to further study the pathogenesis of T-ALL and find novel effective treatment strategies.

MicroRNAs (miRNAs/miRs) are a class of highly conserved non-coding small RNAs of 19 to 25 nucleotide in length that are ubiquitous in organisms and bind to the 3'-untranslated region (UTR) of target mRNAs, inhibit mRNA translation and can regulate gene expression (10,11). miR-221 is one of the miRNAs discovered earlier in humans and is located on the X chromosome p11. 3 (12). In previous years, studies on miR-221 have focused on tumors and inflammation, and studies have confirmed that miR-221 is upregulated and plays a key role in a number of malignant tumors, such as multiple myeloma, bladder cancer and oral squamous cell carcinoma, and inflammatory-related diseases, such as atherosclerosis, osteoarthritis, autoimmune and degenerative diseases (12-16). However, to the best of our knowledge, the role of miR-221 in ALL and its related mechanisms of action have yet not been reported.

In the present study, the effect of miR-221 on human T-ALL cells and its molecular mechanisms were studied.

\section{Materials and methods}

Cell culture. Human T-ALL cell line Jurkat was purchased from The Cell Bank of Type Culture Collection of The Chinese Academy of Sciences. Cells were cultured in $75-\mathrm{cm}^{2}$ flasks with DMEM (Gibco; Thermo Fisher Scientific, Inc.) 
supplemented with $10 \%$ fetal bovine serum (FBS; Gibco; Thermo Fisher Scientific, Inc.), $100 \mathrm{U} / \mathrm{ml}$ penicillin (Nanjing Sunshine Biotech Co., Ltd.) and $100 \mu \mathrm{g} / \mathrm{ml}$ streptomycin (Nanjing Sunshine Biotech Co., Ltd.). Cells were incubated in a $5 \% \mathrm{CO}_{2}$ incubator at $37^{\circ} \mathrm{C}$.

Reverse transcription-quantitative polymerase chain reaction $(R T-q P C R)$. Total RNA was extracted from the human T-ALL cell line using TRIzol reagent (Invitrogen; Thermo Fisher Scientific, Inc.). The concentration of RNA was detected using a NanoDrop ${ }^{\text {TM }} 2000$ spectrophotometer (Thermo Fisher Scientific, Inc.). The RNA samples were stored at $-80^{\circ} \mathrm{C}$ for future use. Then, cDNA was synthesized with a miScript Reverse Transcription kit (Qiagen $\mathrm{GmbH}$ ) according to the manufacturer's protocol. The QuantiFast SYBR Green PCR Kit (Qiagen $\mathrm{GmbH}$ ) was used to perform RT-qPCR using a CFX Connect Real-Time System (Bio-Rad Laboratories, Inc.). GAPDH or U6 was used as the internal control. Thermocycling conditions for qPCR were as follows: Initial denaturation at $95^{\circ} \mathrm{C}$ for $10 \mathrm{~min} ; 37$ cycles of $95^{\circ} \mathrm{C}$ for $15 \mathrm{sec}$ and $55^{\circ} \mathrm{C}$ for $40 \mathrm{sec}$. The $2^{-\Delta \Delta \mathrm{Cq}}$ method (17) was applied for the quantification of relative gene expression. Primer sequences were obtained from GenScript and were as follows: U6 forward, 5'-CTCGCT TCGGCAGCACA-3' and reverse, 5'-AACGCTTCACGAATT TGCGT-3'; GAPDH forward, 5'-TCAACGACCACTTTGTCA AGCTCA-3' and reverse, 5'-GCTGGTGGTCCAGGGGTC TTACT-3'; miR-221 forward, 5'-GCCGAGAGCTACATT GTCTGC-3' and reverse, 5'-CTCAACTGGTGTCGTGGA-3'; PTEN forward, 5'-ATACCAGGACCAGAGGAAACC-3' and reverse, 5'-TTGTCATTATCTGCACGCTC-3'.

Dual-luciferase reporter assay. Next, the mechanism by which miR-221 acted on human T-ALL cell lines was investigated. The target genes of miR-221 were searched using miRanda (microRNA.org), and PTEN was found to be a potential target of miR-221. To confirm the binding sites between miR-221 and the 3'-UTR of PTEN, a dual-luciferase reporter assay was performed. The wild-type (WT-PTEN) and mutant (MUT-PTEN) 3'-UTRs of PTEN were cloned into a pmiR-RB-Report ${ }^{\mathrm{TM}}$ dual-luciferase reporter gene plasmid vector (Guangzhou RiboBio Co., Ltd.). The MUT 3'-UTR of PTEN was constructed using a QuikChange Site-Directed Mutagenesis kit (Stratagene; Agilent Technologies, Inc.) according to the manufacturer's instructions. Jurkat cells $\left(5 \times 10^{4}\right.$ cells/well $)$ were transfected with the reporter constructs and miR-221 mimic (5'-AGCUACAUUGUCUGCUGGGUU UC-3'; Guangzhou Ribobio Co.,Ltd.) or mimic control (5'-CGG UACGAUCGCGGCGGGAUAUC-3'; Guangzhou Ribobio Co., Ltd.) using Lipofectamine ${ }^{\circledR} 2000$ (Invitrogen; Thermo Fisher Scientific, Inc.). Luminescence was assayed $48 \mathrm{~h}$ later using the Dual-Luciferase Reporter Assay System (Promega Corporation) according to the manufacturer's instructions. Results were normalized to the Renilla luminescence from the same vector and shown as the ratio between the various treatments and cells transfected with control vector.

Western blotting. Jurkat cells were washed with ice-cold PBS, and then lysed with radioimmunoprecipitation lysate buffer (Beyotime Institute of Biotechnology), including 1\% PMSF at $4^{\circ} \mathrm{C}$ for $1 \mathrm{~h}$. A BCA assay (Thermo Fisher Scientific,
Inc.) was used to measure the protein concentrations. Protein samples were collected by centrifugation for $5 \mathrm{~min}$ at $4^{\circ} \mathrm{C}$ and $10,000 \mathrm{x}$ g. Proteins ( $40 \mu \mathrm{g}$ per lane) were resolved via $10 \%$ SDS Page, electroblotted to PVDF membranes and then blocked in 5\% non-fat milk at room temperature for $2 \mathrm{~h}$. Membranes were then incubated overnight at $4{ }^{\circ} \mathrm{C}$ with primary antibodies against: PTEN (1:1,000; cat. no. 9188; Cell Signaling Technology, Inc.), Bcl-2 (1:1,000; cat. no. 4223; Cell Signaling Technology, Inc.), Bax (1:1,000; cat. no. 5023; Cell Signaling Technology, Inc.), AKT (1:1,000; cat. no. 4691; Cell Signaling Technology, Inc.), phosphorylated (p)-AKT (1:1,000; cat. no. 4060; Cell Signaling Technology, Inc.) and $\beta$-actin (1:1,000; cat. no. 4970; Cell Signaling Technology, Inc.). Subsequently, the membranes were washed with PBS with $0.1 \%$ Tween-20 (PBST) four times. Membranes were then incubated with horseradish peroxidase-conjugated anti-rabbit IgG secondary antibody (1:2,000; cat. no. 7074; Cell Signaling Technology, Inc.) for $2 \mathrm{~h}$ at room temperature and washed with PBST four times. Finally, ECL reagent (EMD Millipore) was used to visualize protein bands using FluorChem FC3 (ProteinSimple), and AlphaView 3.4.0 software (ProteinSimple) was used for semi-quantification.

Cell transfection. Jurkat cells were seeded into 6-well plates $\left(1 \times 10^{6}\right.$ cells/well) and cultured at $37^{\circ} \mathrm{C}$ for $24 \mathrm{~h}$. Then, cells were transfected with $100 \mathrm{nM}$ inhibitor control (the negative control of miR-221 inhibitor; 5'-CAGUACUUUUGUGUA GUACAA-3'; Guangzhou Ribobio Co., Ltd.), 100 nM miR-221 inhibitor (miR-221 antagonist' 5'-GAAACCCAGCAGACA AUGUAGCU-3'; Guangzhou Ribobio Co., Ltd.), $50 \mathrm{nM}$ mimic control (the negative control of miR-221 mimic; 5'-CGGUAC GAUCGCGGCGGGAUAUC-3'; Guangzhou Ribobio Co., Ltd.), $50 \mathrm{nM}$ miR-221 mimic (miR-221 agonist; 5'-AGCUAC AUUGUCUGCUGGGUUUC-3'; Guangzhou Ribobio Co., Ltd.), $100 \mathrm{nM}$ miR-221 inhibitor $+0.2 \mu \mathrm{M}$ control-small interfering (si)RNA (cat. no. sc-36869; Santa Cruz Biotechnology, Inc.) or $100 \mathrm{nM}$ miR-221 inhibitor $+0.2 \mu \mathrm{M}$ PTEN-siRNA (cat. no. sc-29459; Santa Cruz Biotechnology, Inc.) using Lipofectamine 3000 reagent, according to the manufacturer's instructions. The transfection efficiency was detected $48 \mathrm{~h}$ later using RT-qPCR.

3-(4,5-dimethylthiahiazol-2-y1)-2,5-diphenytetrazolium bromide (MTT) assay. The MTT method was performed to detect cell viability. Jurkat cells were collected after transfection for $48 \mathrm{~h}$, and then cells were seeded into plates (96-well) at a density of $2 \times 10^{4} \mathrm{cells} / \mathrm{ml}$. MTT ( $10 \mu \mathrm{l} / \mathrm{well}$ ) reagent (Beyotime Institute of Biotechnology) was added to each well. Then, the wells were incubated at $37^{\circ} \mathrm{C}$ for another $4 \mathrm{~h}$. DMSO (100 $\mu \mathrm{l}$; Nanjing KeyGen Biotech Co., Ltd.) was used to dissolve the formazan crystals. The absorbance at a wavelength of $490 \mathrm{~nm}$ was measured by Thermo Scientific ${ }^{\mathrm{TM}}$ Multiskan $^{\text {TM }}$ FC Microplate Photometer (Thermo Fisher Scientific, Inc.). The experiment was repeated three times.

Transwell migration and invasion assays. For the invasion assay, Transwell chambers (pore size, $8 \mu \mathrm{m}$; Costar; Corning Inc.) were pre-coated with $30 \mathrm{ml}$ Matrigel (R\&D Systems, Inc.) at $37^{\circ} \mathrm{C}$ for $30 \mathrm{~min}$ and loaded into 24 -well flat-bottomed culture plates. The chambers were loaded into 24-well 
A

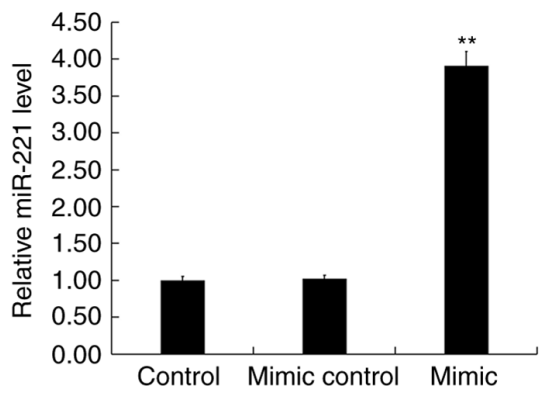

B

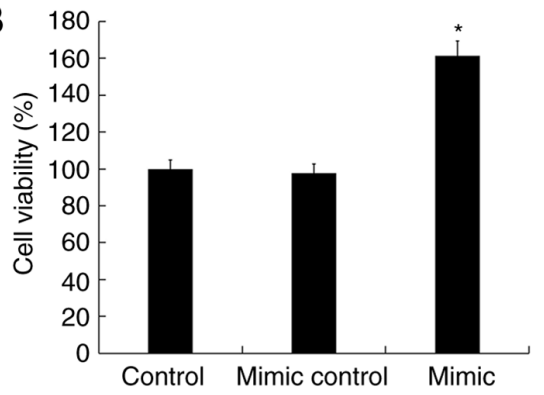

C
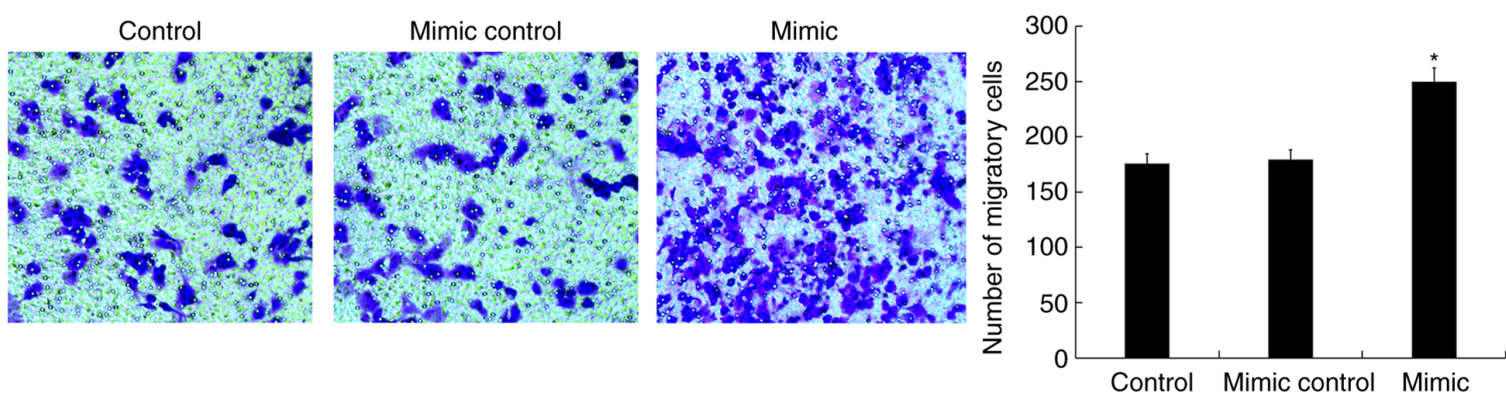

D
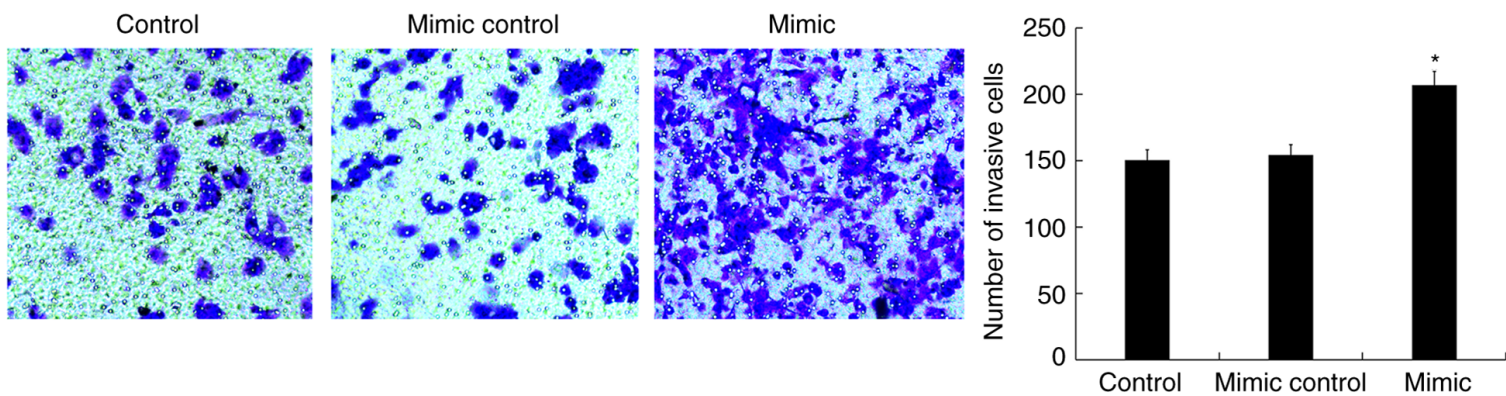

E
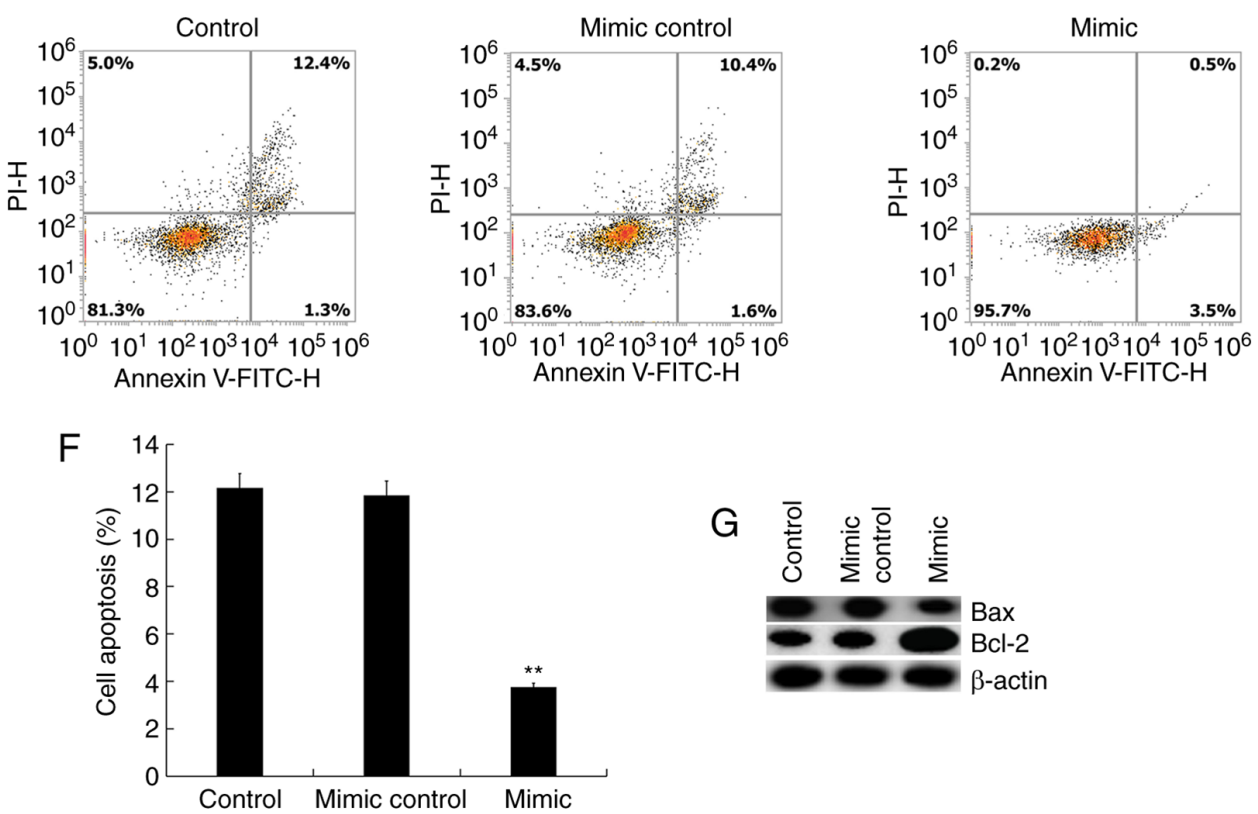

Figure 1. Effect of miR-221 mimic on Jurkat cells. (A) $48 \mathrm{~h}$ after Jurkat cells were transfected with mimic control or miR-221 mimic, the expression of miR-221 in Jurkat cells was detected via reverse transcription-quantitative PCR. (B) Cell viability was determined via 3-(4,5-dimethylthiahiazol-2-y1)-2,5-diphenytetrazolium bromide assay. (C and D) Cell migration and invasion were determined via Transwell assays. (E and F) Cell apoptosis was measured by flow cytometry, and the cell apoptosis rate was calculated and presented. $(\mathrm{G})$ The protein expression levels of Bax and Bcl-2 were detected via western blotting. Data are presented as the mean $\pm \mathrm{SD} .{ }^{*} \mathrm{P}<0.05,{ }^{* *} \mathrm{P}<0.01$ vs. control. miR, microRNA.

flat-bottomed plates without Matrigel for the migration assay. Jurkat cells $\left(2 \times 10^{4}\right)$ were seeded into the upper chamber with serum-free DMEM and $600 \mu$ l DMEM containing 20\% FBS was added to the lower chamber. After incubation at $37^{\circ} \mathrm{C}$ with $5 \% \mathrm{CO}_{2}$ for $24 \mathrm{~h}$, cells on the upper surfaces of the Transwell chambers were scraped with cotton swabs. Then, the membrane 

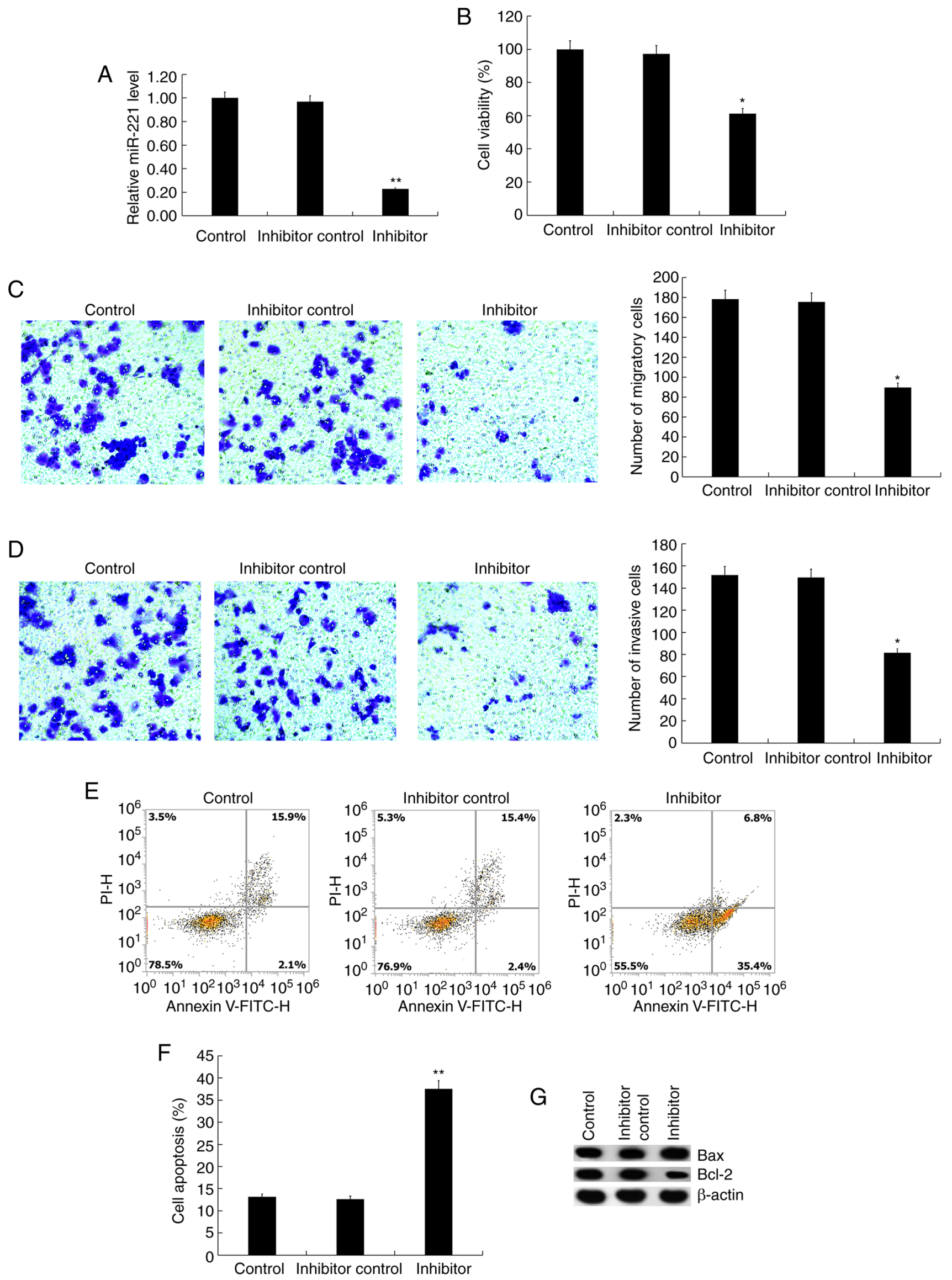

Figure 2. Effect of miR-221 inhibitor on Jurkat cells. (A) At $48 \mathrm{~h}$ after Jurkat cells were transfected with inhibitor control or miR-221 inhibitor, the expression of miR-221 in Jurkat cells was detected via reverse transcription-quantitative PCR. (B) Cell viability was determined via 3-(4,5-dimethylthiahiazol-2-y1)-2,5-diphenytetrazolium bromide assay. (C and D) Cell migration and invasion were determined via Transwell assays. (E and F) Cell apoptosis was measured by flow cytometry, and the cell apoptosis rate was calculated and presented. $(\mathrm{G})$ The protein expression levels of Bax and Bcl-2 were detected via western blotting. Data are presented as the mean $\pm \mathrm{SD} .{ }^{*} \mathrm{P}<0.05,{ }^{* *} \mathrm{P}<0.01$ vs. control. miR, microRNA. 
was fixed with $4 \%$ paraformaldehyde at room temperature for $30 \mathrm{~min}$, and then stained with $0.1 \%$ crystal violet at room temperature for $30 \mathrm{~min}$. The stained cells were imaged and counted under a light microscope (magnification, x100) in five randomly selected fields.

Flow cytometry. The apoptosis of Jurkat cells was detected using the Annexin V-FITC/PI kit [cat. no. 70-AP101-100; Hangzhou Multi Sciences (Lianke) Biotech Co., Ltd.], according to the manufacturer's instructions. Briefly, Jurkat cells were digested using $0.2 \%$ trypsin, followed by washing with PBS three times. Then, the cells were incubated with $5 \mu \mathrm{l}$ Annexin V-FITC and propidium iodide at $4^{\circ} \mathrm{C}$ in the dark for 15 min. Finally, the cell apoptosis rate (early + late apoptosis) was measured using a FACSCalibur ${ }^{\mathrm{TM}}$ flow cytometer (BD Biosciences) with Cell Quest software version 5.1 (BD Biosciences). The assay was performed in triplicate.

Statistical analysis. Experiments were repeated at least three times. Statistical analyses were performed using GraphPad Prism 5 (GraphPad Software, Inc.). Data are presented as the mean \pm standard deviation. An unpaired Student's t-test or one-way analysis of variance (ANOVA) followed by Tukey's test was performed for comparisons between groups. $\mathrm{P}<0.05$ was considered to indicate a statistically significant difference.

\section{Results}

miR-221 upregulation promotes Jurkat cell viability, migration and invasion, and inhibits cell apoptosis. In order to investigate the role of miR-221 in T-ALL, the effect of miR-221 on T-ALL cells was studied. Jurkat cells were transfected with miR-221 mimic or mimic control for $48 \mathrm{~h}$, and it was found that the miR-221 mimic significantly enhanced the expression of miR-221 in Jurkat cells (Fig. 1A). The MTT assay results suggested that compared with the control group, the miR-221 mimic significantly promoted Jurkat cell viability (Fig. 1B). The Transwell assay showed that miR-221 mimic significantly promoted Jurkat cell migration (Fig. 1C) and invasion (Fig. 1D). In addition, it was found that miR-221 mimic significantly inhibited Jurkat cell apoptosis (Fig. 1E and F), and the protein level of Bax in Jurkat cells was notably decreased by miR-221 mimic transfection, whereas Bcl-2 protein expression was increased (Fig. 1G).

miR-221 knockdown inhibits Jurkat cell viability, migration and invasion, and promotes cell apoptosis. Then, the effect of miR-221 knockdown on T-ALL cells was investigated. Jurkat cells were transfected with miR-221 inhibitor or inhibitor control for $48 \mathrm{~h}$, and it was found that the miR-221 inhibitor significantly reduced the expression of miR-221 in Jurkat cells (Fig. 2A). Compared with the control group, miR-221 inhibitor significantly inhibited Jurkat cell viability (Fig. 2B), migration (Fig. 2C) and invasion (Fig. 2D). Besides, as expected, it was found that the miR-221 inhibitor significantly induced Jurkat cell apoptosis (Fig. 2E and F), and enhanced the protein expression level of Bax in Jurkat cells, whereas Bcl-2 protein expression was reduced (Fig. 2G).
PTEN is a direct target of $m i R-221$. To explore the molecular mechanism underlying the effect of miR-221 on human T-ALL cells, potential targets of miR-221 were predicted using the bioinformatics tool microRNA.org (Fig. 3A), and a dual-luciferase reporter assay (Fig. 3B) was performed to show the binding sites between miR-221 and PTEN. Compared with the control group, the miR-221 mimic significantly decreased the mRNA and protein expression of PTEN in Jurkat cells (Fig. 3C and D), whereas the miR-221 inhibitor enhanced the mRNA and protein expression of PTEN in Jurkat cells (Fig. 3E and F). These results demonstrated that PTEN was a direct target of miR-221.

Inhibitory effects of miR-221 inhibitor on Jurkat cells are abolished by PTEN gene silencing. As PTEN was identified as a target of miR-221, it was hypothesized that miR-221 may play a role in the regulation of T-ALL cells by regulating the expression of PTEN. Jurkat cells were transfected with the inhibitor control, miR-221 inhibitor, miR-221 inhibitor + control-siRNA, or miR-221 inhibitor + PTEN-siRNA for $48 \mathrm{~h}$, then cell viability, migration, invasion and cell apoptosis were analyzed. It was first confirmed that compared with the control-siRNA group, PTEN-siRNA significantly reduced PTEN mRNA expression in Jurkat cells (Fig. S1). The findings suggested that the inhibited cell viability (Fig. 4A), migration (Fig. 4B), invasion (Fig. 4C), increased cell apoptosis (Fig. 4D and E), increased Bax protein expression and decreased Bcl-2 protein expression (Fig. 4F) in Jurkat cells induced by transfection with the miR-221 inhibitor were significantly reversed by PTEN silencing.

Phosphatidylinositol 3-kinase (PI3K)/AKT pathway is involved in the effects of miR-221 on Jurkat cells. The results of western blotting showed that compared with the inhibitor control group, miR-221 inhibitor significantly reduced the protein expression of p-AKT in Jurkat cells. Furthermore, the reduced $\mathrm{p}$-AKT protein expression in Jurkat cells induced by the miR-221 inhibitor was reversed by PTEN-siRNA (Fig. 5A and B). The protein expression of AKT did not change notably in each group.

\section{Discussion}

ALL is a common and life-threatening hematological malignancy. Relapsed/refractory ALL has poor prognosis rates. For relapsed ALL, the median survival ranges from 4 to 8 months, with a 5-year overall survival of $<10 \%(18-20)$.

miRNAs are a type of non-coding small RNA with 19-25 nucleotides, which have roles in post-transcriptional regulation and have been found to silence a broad range of target genes $(10,11)$. The abnormal expression of miRNA plays an essential role in cancer occurrence and progression. For instance, miR-221, an oncogenic miRNA, which belongs to the miR-221/222 family, is involved in cancer invasion and migration in multiple types of cancer, including colorectal cancer, renal cell carcinoma and luminal breast cancer (21-23). The high expression of miR-221 has been found to directly inhibit target genes, such as PTEN (24). PTEN, an important tumor suppressor, is mutated in the majority of advanced tumors and plays an important role in modulating the PI3K/AKT pathway (25). 


\section{A miR-221: 3'cuuugggucgUCUGUUACAUCGa5' \\ II:: : |||||| \\ PTEN: 5'aguugaaaaAGGUUGUGUAGCu5'}

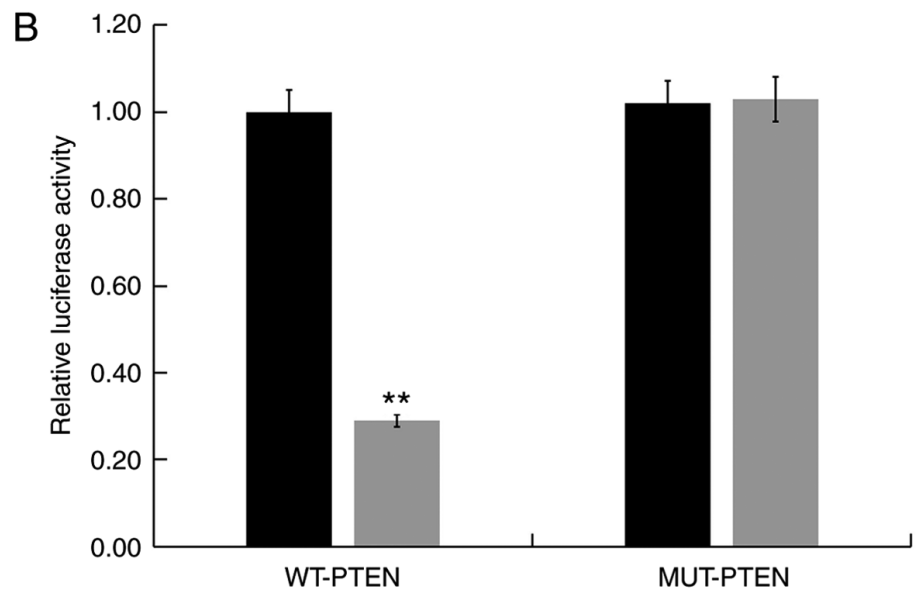

Mimic control miR-221
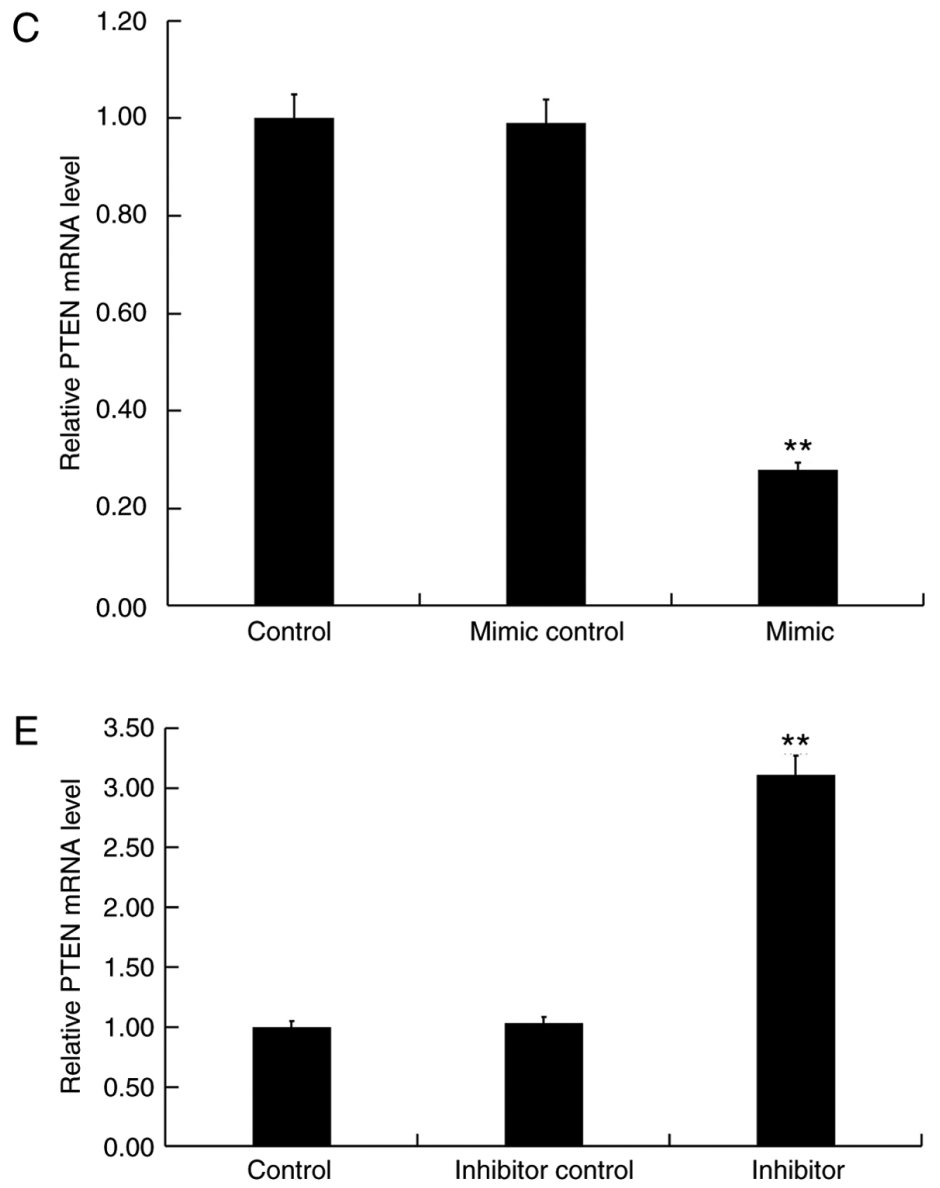
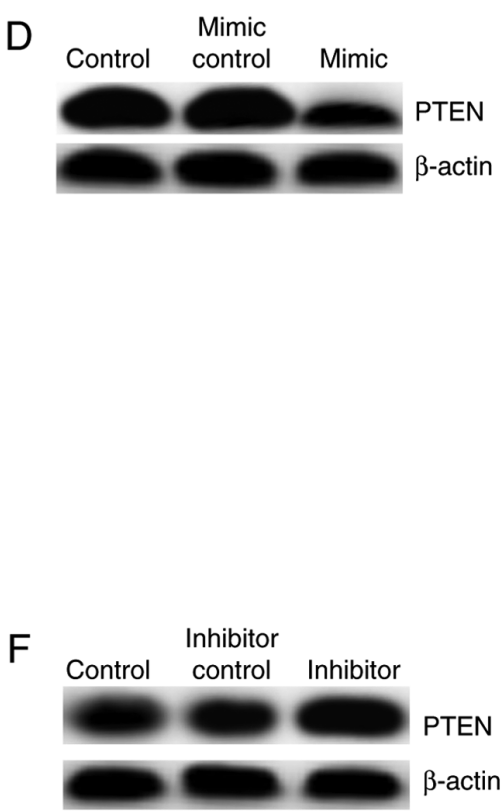

Figure 3. PTEN is a direct target of miR-221. (A) Binding sites between miR-221 and 3'UTR of PTEN was predicted using microRNA target site prediction software. (B) Dual-luciferase reporter assay of a reporter containing WT-PTEN or a MUT-PTEN 3'UTR is presented. All data are presented as the mean \pm SD of three independent experiments. ${ }^{* *} \mathrm{P}<0.01$ vs. mimic control. (C and D) $48 \mathrm{~h}$ after Jurkat cells were transfected with mimic control or miR-221 mimic, the mRNA and protein expression of PTEN was detected via RT-qPCR and western blotting. (E and F) $48 \mathrm{~h}$ after Jurkat cells were transfected with inhibitor control or miR-221 inhibitor, the mRNA and protein expression of PTEN was measured via RT-qPCR and western blotting. Data are presented as the mean $\pm \mathrm{SD}$. ${ }^{* *} \mathrm{P}<0.01$ vs. control. miR, microRNA; UTR, untranslated region; PTEN, phosphatase and tensin homologue deleted on chromosome 10; WT, wild-type; MUT, mutant; RT-qPCR, reverse transcription-quantitative PCR.

The present study verified that miR-221 upregulation significantly promoted human T-ALL cell viability, migration and invasion, and inhibited cell apoptosis. Whereas,
miR-221 downregulation significantly inhibited human T-ALL cell viability, migration and invasion, and induced cell apoptosis. Then, bioinformatics analysis using miRanda and 

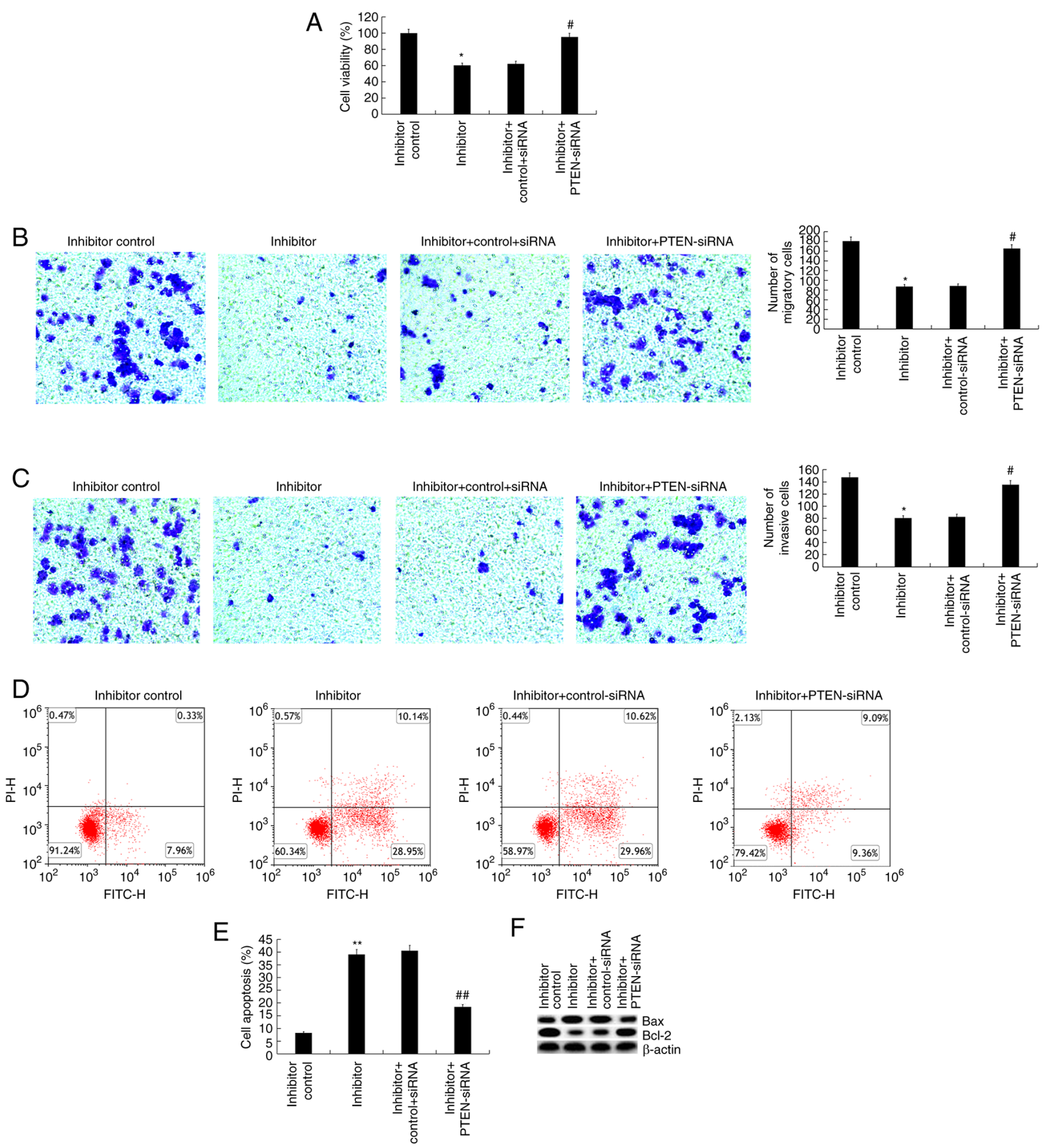

$\mathrm{F}$

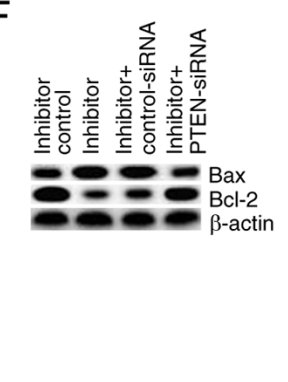

Figure 4. Effect of PTEN silencing on miR-221 inhibitor-transfected Jurkat cells. (A) $48 \mathrm{~h}$ after Jurkat cells were transfected with inhibitor control, miR-221 inhibitor, miR-221 inhibitor + control-siRNA or miR-221 inhibitor + PTEN-siRNA, cell viability was determined via 3-(4,5-dimethylthiahiazol-2-y1)-2,5-diphenytetrazolium bromide assay. (B and C) Cell migration and invasion were determined via Transwell assays. (D and E) Cell apoptosis was measured by flow cytometry, and the cell apoptosis rate was calculated and presented. (F) The protein expression levels of Bax and Bcl-2 were detected via western blotting. Data are presented as the mean $\pm \mathrm{SD}$. ${ }^{*} \mathrm{P}<0.05,{ }^{* *} \mathrm{P}<0.01$ vs. inhibitor control group; ${ }^{\#} \mathrm{P}<0.05,{ }^{\# \#} \mathrm{P}<0.01$ vs. inhibitor + control-siRNA group. PTEN, phosphatase and tensin homologue deleted on chromosome 10; miR, microRNA; siRNA, small interfering RNA.

the dual-luciferase reporter assay revealed that PTEN was a direct target of miR-221. Moreover, it is worth noting that the effects of miR-221 knockdown on T-ALL cells, such as cell viability, migration, invasion and apoptosis, were reversed by PTEN silencing.
Abnormal activation of the PI3K/AKT signaling pathway plays an important role in tumor signaling during important pathological processes of tumor cell growth, proliferation and apoptosis. Studies have shown that the inhibition of PI3K protein activation can make drug-resistant tumor cells sensitive 
A

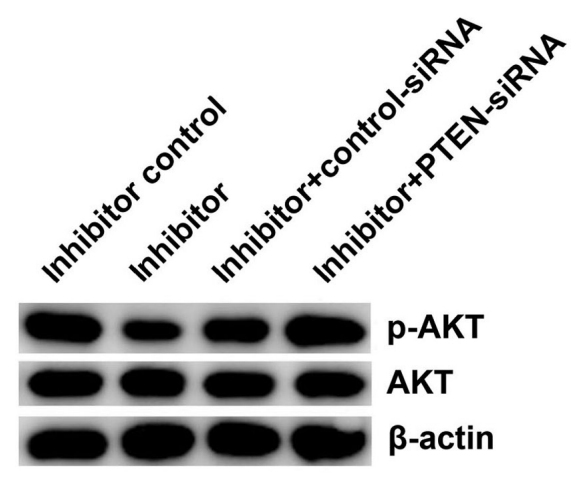

B

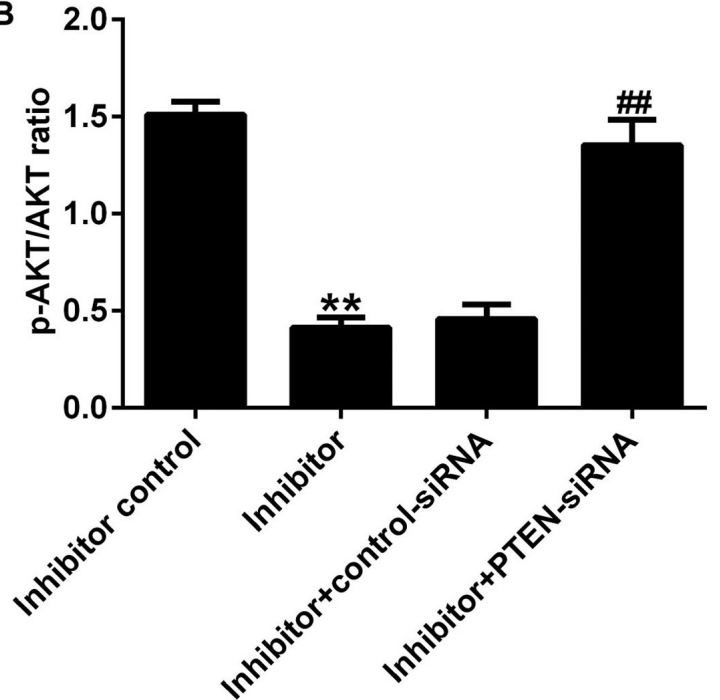

Figure 5. Effect of miR-221 inhibitor on the PI3K/AKT pathway in Jurkat cells. (A) $48 \mathrm{~h}$ after Jurkat cells were transfected with inhibitor control, miR-221 inhibitor, miR-221 inhibitor + control-siRNA or miR-221 inhibitor + PTEN-siRNA, the protein expression of p-AKT and AKT was detected via western blotting. (B) The ratio of p-AKT/AKT was calculated and presented. Data are presented as the mean $\pm \mathrm{SD}$. ${ }^{* *} \mathrm{P}<0.01$ vs. inhibitor control group; ${ }^{* \#} \mathrm{P}<0.01$ vs. inhibitor + control-siRNA group. PTEN, phosphatase and tensin homologue deleted on chromosome 10; miR, microRNA; siRNA, small interfering RNA; PI3K, phosphatidylinositol 3-kinase; p-, phosphorylated.

to chemotherapeutic drugs $(26,27)$. AKT plays a pivotal role in PI3K signaling, in which phosphorylation of AKT can activate or block multiple signaling pathways, including Bcl-2/Bax, mTOR and Caspase-9 $(28,29)$. Among them, the $\mathrm{Bcl}-2 / \mathrm{Bax}$ pathway protein plays a key role in the process of apoptosis and is also an important downstream target of AKT signaling (30). Apoptosis is the process of cell death under physiological or pathological conditions under the control of multiple genes. The Bcl-2 gene family are important regulators of apoptosis (31). The Bcl-2 protein family can be divided into proapoptotic proteins and anti-apoptotic proteins, among which Bax is one of pro-apoptotic proteins and Bcl-2 is one of the anti-apoptotic proteins (32). In the present study, flow cytometry was performed to detect apoptosis, and the protein expression levels of Bcl-2, Bax and p-AKT were measured via western blotting. The results showed that transfection with a miR-221 mimic significantly inhibited the apoptosis of Jurkat cells, enhanced Bcl-2 and decreased Bax expression. Whereas, miR-221 inhibitor could significantly induce apoptosis of Jurkat cells, reduce Bcl-2 and p-AKT protein expression, and increase Bax expression, and all these changes were reversed by PTEN silencing.

In conclusion, the current study showed that miR-221 downregulation significantly reduced the viability, migration and invasion of Jurkat cells and induced apoptosis by targeting PTEN. miR-221 downregulation inhibited human T-ALL cell growth by regulating the PTEN/PI3K-AKT signaling pathway. Therefore, miR-221 may be a novel potential therapeutic target for T-ALL treatment. However, this is only a preliminary study of the role of miR-221 in T-ALL. In order to fully elucidate the role of miR-221 in T-ALL, further experimental research is required. For example, the expression of miR-221 in patients with T-ALL and cell lines should be detected. The role of miR-221 in other T-ALL cell lines should be also investigated. Besides, the relationship between the expression of miR-221 and the clinical features of T-ALL patients requires further research. Moreover, the role of miR-221 in T-ALL should be investigated in vivo. In future research, we will further study these topics.

\section{Acknowledgements}

Not applicable.

\section{Funding}

The present study was supported by the Zhejiang Provincial Education Department General Research Project (grant no. Y201737673).

\section{Availability of data and materials}

The datasets used and/or analyzed during the current study are available from the corresponding author on reasonable request.

\section{Authors' contributions}

LZ contributed to study design, data collection, statistical analysis, data interpretation and manuscript preparation. $\mathrm{ZB}$, JS, LS and YC contributed to data collection, statistical analysis and manuscript preparation. PZ and YW contributed to the data collection and statistical analysis. LZ and ZB confirm the authenticity of all the raw data. All authors read and approved the final manuscript.

\section{Ethics approval and consent to participate}

Not applicable.

\section{Patient consent for publication}

Not applicable. 


\section{Competing interests}

The authors declare that they have no competing interests.

\section{References}

1. Hunger SP and Mullighan CG: Acute lymphoblastic leukemia in children. N Engl J Med 373: 1541-1552, 2015.

2. Rose-Inman H and Kuehl D: Acute leukemia. Hematol Oncol Clin North Am 31: 1011-1028, 2017.

3. Tallen G, Ratei R, Mann G, Kaspers G, Niggli F, Karachunsky A, Ebell W, Escherich G, Schrappe M, Klingebiel T, et al: Long-term outcome in children with relapsed acute lymphoblastic leukemia after time-point and site-of-relapse stratification and intensified short-course multidrug chemotherapy: Results of trial ALL-REZ BFM 90. J Clin Oncol 28: 2339-2347, 2010.

4. Ronson A, Tvito A and Rowe JM: Treatment of relapsed/refractory acute lymphoblastic leukemia in adults. Curr Oncol Rep 18 39, 2016.

5. Kuhlen M, Willasch AM, Dalle JH, Wachowiak J, Yaniv I, Ifversen M, Sedlacek P, Guengoer T, Lang P, Bader P, et al: Outcome of relapse after allogeneic HSCT in children with ALL enrolled in the ALL-SCT 2003/2007 trial. Br J Haematol 180 82-89, 2018.

6. Belver L and Ferrando A: The genetics and mechanisms of T cell acute lymphoblastic leukaemia. Nat Rev Cancer 16: 494-507, 2016.

7. Hefazi M and Litzow MR: Recent advances in the biology and treatment of $\mathrm{T}$ cell acute lymphoblastic leukemia. Curr Hematol Malig Rep 13: 265-274, 2018.

8. Teachey DT and Pui CH: Comparative features and outcomes between paediatric T-cell and B-cell acute lymphoblastic leukaemia. Lancet Oncol 20: e142-e154, 2019.

9. Ghelli Luserna Di Rorà A, Iacobucci I, Imbrogno E, Papayannidis C, Derenzini E, Ferrari A, Guadagnuolo V, Robustelli V, Parisi S, Sartor C, et al: Prexasertib, a Chk1/Chk2 inhibitor, increases the effectiveness of conventional therapy in B-/T-cell progenitor acute lymphoblastic leukemia. Oncotarget 7: 53377-53391, 2016.

10. Bartel DP: MicroRNA: Genomics, biogenesis, mechanism, and function. Cell 116: 281-297, 2004

11. Shukla GC, Singh J and Barik S: MicroRNAs: Processing, maturation, target recognition and regulatory functions. Mol Cell Pharmacol 3: 83-92, 2011.

12. Zhao JJ, Chu ZB, Hu Y, Lin J, Wang Z, Jiang M, Chen M, Wang X, Kang Y, Zhou Y, et al: Targeting the miR-221-222/PUMA/BAK/BAX pathway abrogates dexamethasone resistance in multiple myeloma. Cancer Res 75: 4384-4397, 2015.

13. Liu H, Chang JK, Hou JQ, Zhao ZH and Zhang LD: Inhibition of miR-221 influences bladder cancer cell proliferation and apoptosis. Eur Rev Med Pharmacol Sci 21: 3193-3199, 2017.

14. Zhou L, Jiang F, Chen X, Liu Z, Ouyang Y, Zhao W and Yu D: Downregulation of miR-221/222 by a microRNA sponge promotes apoptosis in oral squamous cell carcinoma cells through upregulation of PTEN. Oncol Lett 12: 4419-4426, 2016.

15. Chistiakov DA, Sobenin IA, Orekhov AN and Bobryshev YV: Human miR-221/222 in physiological and atherosclerotic vascular remodeling. Biomed Res Int 2015: 354517, 2015.

16. Marques-Rocha JL, Samblas M, Milagro FI, Bressan J, Martínez JA and Marti A: Noncoding RNAs, cytokines, and inflammation-related diseases. FASEB J 29: 3595-3611, 2015.
17. Livak KJ and Schmittgen TD: Analysis of relative gene expression data using real-time quantitative PCR and the 2(-Delta Delta C(T)) method. Methods 25: 402-408, 2001.

18. Göekbuget N, Dombret H, Ribera JM, Fielding AK, Advani A, Bassan R, Chia V, Doubek M, Giebel S, Hoelzer D, et al: International reference analysis of outcomes in adults with $\mathrm{B}$-precursor $\mathrm{Ph}$-negative relapsed/refractory acute lymphoblastic leukemia. Haematologica 101: 1524-1533, 2016.

19. Gökbuget N, Stanze D, Beck J, Diedrich H, Horst HA Hüttmann A, Kobbe G, Kreuzer KA, Leimer L, Reichle A, et al: Outcome of relapsed adult lymphoblastic leukemia depends on response to salvage chemotherapy, prognostic factors, and performance of stem cell transplantation. Blood 120: 2032-2041, 2012.

20. Oriol A, Vives S, Hernández-Rivas JM, Tormo M, Heras I, Rivas C, Bethencourt C, Moscardó F, Bueno J, Grande C, et al: Outcome after relapse of acute lymphoblastic leukemia in adult patients included in four consecutive risk-adapted trials by the PETHEMA study group. Haematologica 95: 589-596, 2010.

21. Dentelli P, Traversa M, Rosso A, Togliatto G, Olgasi C, Marchiò C, Provero P, Lembo A, Bon G, Annaratone L, et al: miR-221/222 control luminal breast cancer tumor progression by regulating different targets. Cell Cycle 13: 1811-1826, 2014.

22. Qin J and Luo M: MicroRNA-221 promotes colorectal cancer cell invasion and metastasis by targeting RECK. FEBS Lett 588: 99-104, 2014.

23. Lu GJ, Dong YQ, Zhang QM, Di WY, Jiao LY, Gao QZ and Zhang CG: miRNA-221 promotes proliferation, migration and invasion by targeting TIMP2 in renal cell carcinoma. Int J Clin Exp Pathol 8: 5224-5229, 2015.

24. Ye X, Bai W, Zhu H, Zhang X, Chen Y, Wang L, Yang A, Zhao J and Jia L: MiR-221 promotes trastuzumab-resistance and metastasis in HER2-positive breast cancers by targeting PTEN. BMB Rep 47: 268-273, 2014.

25. Salmena L, Carracedo A and Pandolfi PP: Tenets of PTEN tumor suppression. Cell 133: 403-414, 2008.

26. Fischer B, Frei C, Moura U, Stahel R and Felley-Bosco E: Inhibition of phosphoinositide-3 kinase pathway down regulates ABCG2 function and sensitizes malignant pleural mesothelioma to chemotherapy. Lung Cancer 78: 23-29, 2012

27. Rahmani M, Aust MM, Attkisson E, Williams DC Jr, Ferreira-Gonzalez A and Grant S: Dual inhibition of Bcl-2 and Bcl-xL strikingly enhances PI3K inhibition-induced apoptosis in human myeloid leukemia cells through a GSK3- and Bim-dependent mechanism. Cancer Res 73: 1340-1351, 2013.

28. Zhou BH, Tan PP, Jia LS, Zhao WP, Wang JC and Wang HW: PI3K/AKT signaling pathway involvement in fluoride-induced apoptosis in C2C12 cells. Chemosphere 199: 297-302, 2018.

29. Martini M, De Santis MC, Braccini L, Gulluni F and Hirsch E: PI3K/AKT signaling pathway and cancer: An updated review. Ann Med 46: 372-383, 2014.

30. Vachhani P, Bose P, Rahmani M and Grant S: Rational combination of dual PI3K/mTOR blockade and Bcl-2/-xL inhibition in AML. Physiol Genomics 46: 448-456, 2014.

31. Radha G and Raghavan SC: BCL2: A promising cancer therapeutic target. Biochim Biophys Acta Rev Cancer 1868: 309-314, 2017.

32. Brown LM, Hanna DT, Khaw SL and Ekert PG: Dysregulation of BCL-2 family proteins by leukemia fusion genes. J Biol Chem 292: 14325-14333, 2017.

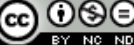

This work is licensed under a Creative Commons Attribution-NonCommercial-NoDerivatives 4.0 International (CC BY-NC-ND 4.0) License. 